\title{
KAJIAN MODAL SOSIAL PADA KELOMPOK TANI SUKA MAJU DAN KELOMPOK TANI TUMOU TOU DI DESA KOPIWANGKER KECAMATAN LANGOWAN BARAT KABUPATEN MINAHASA
}

\author{
Hansen Jeremia Wowiling \\ Martha Mareyke Sendow \\ Welson Marthen Wangke
}

\begin{tabular}{ll}
\hline Naskah diterima melalui Website Jurnal Ilmiah Agrisosioekonomi Fakultas Pertanian UNSRAT & : Jumat, 19 April 2019 \\
Disetujui diterbitkan & $:$ Sabtu, 27 April 2019 \\
\hline
\end{tabular}

\begin{abstract}
The research was conducted from September 2018 to February 2019, starting from preparation to preparing the report. The sampling method in this study was to use the Total Sampling method with a number of samples taken as many as $100 \%$ of the members of two farmer groups namely Suka Maju farmer groups as many as 17 respondents and Tumou Tou farmer groups as many as 17 respondents. The total number of respondents was 34 farmers. The data used are primary data and secondary data. Primary data was collected by interviewing all respondents with the help of a list of questions prepared before. Secondary data was collected from documents owned by both farmer groups, local bookstores, the internet through google search engines in the form of books and "skripsi" related to the topic of this research, namely farmers' social capital. Data analysis was carried out descriptively which was presented in table form and then interpreted. The results showed that the elements of social capital namely norms, networks, beliefs, reciprocal relationships, and values have been able to improve the existence and cohesiveness of Suka Maju farmer groups because the social capital of Suka Maju farmer groups is very good compared to Tumou Tou farmer groups. Viewed from all sides, the Tani Suka Maju group has better social capital than the Tumou Tou farmer group. Thus to improve the existence and cohesiveness of Tumou Tou farmer group like Suka Maju farmer group, it is necessary to improve the quality of social capital as owned by farmer groups Suka Maju. ${ }^{*}{ }^{2}{ }^{*}$
\end{abstract}

Keywords: Describing, knowledge, performance, Minahasa Regency

\begin{abstract}
ABSTRAK
Penelitian ini dilaksanakan pada bulan September 2018 hingga Februari 2019, mulai dari persiapan sampai pada penyusunan laporan. Data yang digunakan adalah Data Primer dan Data Sekunder. Metode pengambilan sampel dalam penelitian ini adalah dengan menggunakan metode Total Sampling dengan jumlah sampel diambil sebanyak 100\% dari anggota dua kelompok tani yaitu kelompok tani Suka Maju sebanyak 17 responden dan kelompok tani Tumou Tou sebanyak 17 responden. Jumlah responden sebanyak 34 petani. Data primer dikumpulkan dengan wawancara pada semua responden dengan bantuan daftar pertanyaan yang sudah disiapkan sebelumnya. Data sekunder dikumpulkan dari dokumen yang dimiliki oleh kedua kelompok tani, toko buku lokal, internet melalui mesin pencari google berupa buku dan skripsi yang berkaitan dengan topik penelitian ini yaitu modal sosial petani. Analisis data dilakukan secara deskriptif yang disajikan dalam bentuk Tabel dan kemudian diinterpretasikan. Hasil penelitian menunjukkan bahwa unsur-unsur modal sosial yaitu norma, jaringan, kepercayaan, hubungan timbal balik, dan nilai-nilai telah mampu meningkatkan eksistensi serta kekompakan kelompok tani Suka Maju karena modal dari kelompok tani Suka Maju sangat baik di banding dengan kelompok tani Tumou Tou. Ditinjau dari segala sisi kelompok Tani Suka Maju memiliki modal sosial yang lebih baik dari kelompok tani Tumou Tou. Dengan demikian untuk meningkatkan eksistensi dan kekompakan kelompok tani Tumou Tou perlu meningkatkan kualitas modal sosial seperti yang dimiliki oleh kelompok tani Suka Maju. ${ }^{* \text { eprm* }}$
\end{abstract}

Kata kunci : Menggambarkan, pengetahuan, performa, Kabupaten Minahasa 


\section{PENDAHULUAN}

\section{Latar Belakang}

Indonesia adalah negara agraris dengan kondisi alam yang mendukung dengan adanya lahan yang luas, keragaman hayati yang melimpah, serta beriklim tropis sangat baik sehingga setiap musim bisa bercocok tanam. Realita sumberdaya alam seperti ini seharusnya mampu membangkitkan Indonesia menjadi negara yang makmur. Meskipun belum terpenuhi, pertanian menjadi salah satu sektor yang memiliki peran yang sangat nyata sebagai sumber mata pencarian penduduk karna lebih dari 31 Juta jiwa Indonesia adalah berprofesi sebagai petani di sektor pertanian, demikian data yang dilansir oleh Badan Pusat Statistika. Begitu juga dengan penduduk di Provinsi Sulawesi Utara khusunya Kabupaten Minahasa kebanyakan sumber penghasilan masyarakat ada di bidang Pertanian.

Sebagian besar penduduk Kabupaten Minahasa menggantungkan hidupnya pada sektor pertanian. Lebih dari 42 ribu penduduk Kabupaten Minahasa berprofesi sebagai petani di sektor pertanian.

Kebijakan yang ditempuh pemerintah Kabupaten Minahasa untuk mewujudkan tujuan pembagunan nasional diantaranya adalah dengan peningkatan kehidupan ekonomi yang dilakukan melalui pembangunan pertanian. Salah satu kebijakan mendasar untuk mengatasi masalah dalam pertanian adalah membentuk kelompok tani.

Penjabaran modal sosial adalah penampilan organisasi sosial, yang dapat memperbaiki efisiensi masyarakat dengan memfasilitasi adanya koordinasi dan kerjasama bagi keuntungan bersama. (Putnam, Et Al. Dalam Suharto, 2007).

Kelompok tani adalah kumpulan para petani yang terikat secara formal atas dasar keserasian, kesamaan kondisi lingkungan, keakraban kepentingan bersama dan saling mempercayai, serta mempunyai pimpinan untuk mencapai satu tujuan yang sama. Pembentukan kelompok tani merupakan suatu usaha pembagunan pertanian yang berfungsi untuk memperlancar hasil pertanian dan memberikan wadah yang kokoh di pedesaan dan merupakan tempat untuk memperkuat kerjasama diantara para petani dalam kelompok untuk mengadapi berbagai tantangan.

Desa Kopiwangker merupakan salah satu desa yang terletak di Kecamatan Langowan Barat, Kabupaten Minahasa, yang terletak di daerah pegunungan yang sebagian besar penduduknya bermata pencaharian sebagai petani dan tergabung dalam kelompok-kelompok tani. Mayoritas petani di desa Kopiwangker ini bercocok tanam seperti padi, tomat, mentimun, sayur-sayuran, jagung dan lain- lain. Petani di desa ini sering mengalami gagal panen yang diakibatkan banyak faktor, diantaranya adalah faktor cuaca, modal dan pengetahuan yang masih minim tentang budidaya tani. Pada saat mengalami gagal panen tidak jarang petani putus harapan menemukan cara-cara bertani dengan baik. Masyarakat sepakat membentuk kelompok tani. Terdapat 3 kelompok tani di Desa Kopiwangker yang anggotanya masing-masing berbeda. Akan tetapi berdasarkan keterangan yang diperoleh dari Balai Penyuluhan Pertanian Perikanan dan Kehutanan (BP3K), Kecamatan Langowan Barat, diantara ke 2 kelompok tani di Desa Kopiwangker hanya 1 kelompok tani yang di nilai aktif yaitu kelompok tani Suka Maju. Dan kelompok tani lainya yaitu Kelompok Tani Tumou Tou di nilai kurang aktif dalam usaha kelompok taninya.

Kelompok tani mempunyai tujuan yaitu untuk mendukung dan membantu masyarakat dalam mengelola lahan pertanian dengan baik dan mengalami perubahan ke arah yang lebih baik dan dapat meningkatkan produksi pertanian dengan maksimal sehingga para petani yang tergabung dalam kelompok tani merasakan dampak yang positif bagi kehidupanya yang berujung pada kesejahteraan petani. Kelompok tani Suka Maju terbentuk pada tahun 11 November 2002 yang beranggotakan 17 orang dan sudah termasuk di dalamnya pengurus 3 orang dan tergolong dalam kelompok tani tingkat lanjut. Sedangkan kelompok tani Tumou Tou terbentuk pada tahun 2001 yang beranggotakan 17 orang dan sudah termasuk di dalamnya pengurus 3 orang, tergolong dalam kelompok tani tingkat pemula.

Keberlangsungan kelompok tani membutukan adanya modal (capital) yang merupakan pondasi suatu usaha. Hal tersebut dibuktikan dengan sering dibahasanya modal (capital) oleh para ekonomi. Khususnya modal ekonomi atau finansial (financial capital). Selain modal finansial, modal yang dapat dijadikan untuk investasi di masa depan adalah modal sosial (Suharto, 2007).

Berdasarkan latar belakang yang diuraikan maka peneliti merasa penting untuk mengkaji modal sosial dalam Kelompok Tani Suka Majudan Kelompok Tani Tumou Tou di Desa Kopiwangker, Kecamatan Langowan Barat,Kabupaten Minahasa sebagai perbandingan.

\section{Rumusan Masalah Penelitian}

Rumusan masalah dalam penelitian ini adalah bagaimana modal sosial yang terdapat pada Kelompok Tani Suka Majudan Kelomok Tani Tumou Tou. 


\section{Tujuan Penelitian}

Penelitian ini bertujuan untuk mengkaji modal sosial pada Kelompok Tani Suka Maju dan Kelompok Tani Tumou Tou di Desa Kopiwangker, Kecamatan. Langowan Barat, Kabupaten Minahasa.

\section{Manfaat Penelitian}

Penelitian ini diharapkan dapat memberikan manfaat kepada petani terlebih khusus anggota kelompok Tani Suka Maju dan Kelomok Tani Tumou Tou mengenai Modal Sosial yang terdapat pada kelompok Tani Suka Maju dan Kelomok Tani Tumou Tou. Dan bahan masukan bagi kelompok tani lainnya yang terdapat di Desa Kopiwangker

\section{METODE PENELITIAN}

\section{Waktu dan Lokasi Penelitian}

Penelitian ini dilaksanakan di Desa Kopiwangker, Kecamatan Langowan Barat, Kabupaten Minahasa, selama 5 bulan mulai dari persiapan, pengambilan data sampai pada penyusunan laporan hasil penelitian.

\section{Metode Pengumpulan Data}

Metode pengumpulan data dalam penelitian ini menggunakan data primer yang diperoleh langsung dari responden dan data sekunder dan yang diperoleh dari pemerintah Desa Kopiwangker dan Balai Penyuluhan Pertanian Perikanan dan Kehutanan. Kecamatan Langowan Barat

\section{Metode Pengambilan Sampel}

Metode pengambilan sampel anggota kelompok tani dalam penelitian ini adalah dengan menggunakan metode sampling jenuh yang studinya disebut studi populasi.

\section{Konsep Pengukuran Variabel}

Konsep Pengukuran Variabel

Variabel, sub variabel dan indikator penelitian yang dikaji dalam penelitian ini adalah:

1. Karakteristik kelompok tani.

2. Karakteristik responden, mencakup

1) Umur, yaitu umur anggota kelompok tani yang dinyatakan dalam tahun.

2) Tingkat pendidikan, dilihat dari pendidikan terakhir responden

3. Modal sosial

1) Norma berikut:

Kriteria indikator pengukurannya sebagai
a. Peraturan
b. Sanksi

\section{c. Keadilan}

2) Jaringan

Kriteria pengukuran jaringan, antara lain:
a. Petani dengan petani
b. Petani dengan petani kelompok lain
c. Petani dengan instansi pemerintah

3) Kepercayaan

Kriteria pengukuran kepercayaan:
a. Hubungan sosial
b. Harapan

4) Hubungan timbal balik (Reciprocity)

Reciprocity merupakan salah satu kompenen modal sosial yang diwarnai oleh kecenderungan saling bertukar pikiran.

5) Nilai-nilai

Kriteria pengukuran dari nilai-nilai
a. Kerja keras
b. Kompetisi
c. Prestasi

\section{Metode Analisis Data}

Metode analisis data yang digunakan dalam penelitian ini yaitu analisis deskriptif kemudian diinterpretasi untuk penarikan kesimpulan.

\section{Metode Penelitian}

Metode penelitian yang digunakan dalam penelitian ini yaitu menggunakan metode penelitian kualitatif.

\section{HASIL DAN PEMBAHASAN}

\section{Deskripsi Daerah Penelitian}

Desa Kopiwangker sebuah desa yang terletak di wilayah Kecamatan Langowan Barat, Kabupaten Minahasa, Provinsi Sulawesi Utara, dan terdiri dari 4 Jaga/Dusun, dengan batas geografis wilayah sebgai berikut:
Sebelah Utara
: Taraitak
Sebelah Timur
: Paslaten
Sebelah Barat
: Tumaratas
: Walewangko

Desa Kopiwangker memiliki jumlah penduduk 1.650 orang dengan luas Wilayah 1.719 Ha.

\section{Gambaran Umum Kelompok Tani}

Gambaran Umum Kelompok Tani dapat di lihat dalam Tabel 2.

\begin{tabular}{llllll} 
Tabel 2. Gambaran Umum Kelompok Tani & & \\
\hline $\begin{array}{l}\text { Nama } \\
\text { Kelompok } \\
\text { Tani }\end{array}$ & Lokasi & $\begin{array}{l}\text { Tahun } \\
\text { Berdiri }\end{array}$ & $\begin{array}{l}\text { Jumlah } \\
\text { Anggota }\end{array}$ & Jenis Usaha & $\begin{array}{l}\text { AD } \\
\text { dan } \\
\text { ART }\end{array}$ \\
\hline $\begin{array}{l}\text { Suka } \\
\text { Maju }\end{array}$ & $\begin{array}{l}\text { Desa } \\
\text { Kopiwangker }\end{array}$ & 2002 & 17 orang & $\begin{array}{l}\text { Padi Sawah, } \\
\text { Holtikultura, } \\
\text { jagung }\end{array}$ & Ada \\
$\begin{array}{l}\text { Tumou } \\
\text { Tou }\end{array}$ & Desa & 2001 & 17 orang & $\begin{array}{l}\text { Padi, Tomat, } \\
\text { Holtikultura }\end{array}$ & Ada \\
\hline Kata Primer 2019. Diolah. & & & &
\end{tabular}




\section{Karakteristik Responden \\ Umur Responden}

Tingkat umur mempengarui kemampuan seseorang dalam melakukan aktifitas maupun konsep berpikir. Anggota kelompok tani yang memiliki umur muda tentunya memiliki kondisi fisik yang lebih kuat, keinginan untuk mencoba hal baru, serta memiliki daya berpikir yang lebih kreatif dibandingkan dengan yang berumur tua. Selain itu, tenaga kerja yang lebih tua cenderung lebih menjaga kesehatannya. Komposisi umur responden disajikan pada Tabel 3 dan Tabel 4.

Tabel 3. Jumlah Responden menurut Tingkat Umur Kelompok

\begin{tabular}{cccc}
\multicolumn{3}{c}{ Tani Suka Maju } & \\
\hline No & Umur (Tahun) & $\begin{array}{c}\text { Jumlah } \\
\text { Responden } \\
\text { (Orang) }\end{array}$ & Persentase (\%) \\
\hline $\mathbf{1}$ & $31-40$ & 11 & 64,70 \\
$\mathbf{2}$ & $41-50$ & 4 & 23,52 \\
$\mathbf{3}$ & $51-60$ & 2 & 11,76 \\
\hline & Jumlah & 17 & 100,00 \\
\hline
\end{tabular}

Data Primer 2019. Diolah.

Hasil penelitian menujukan bahwa usia responden kelompok tani Suka Maju berkisar antara 31-60 tahun, dan responden yang paling banyak adalah yang berumur 3140 tahun yaitu sebanyak 11 orang atau 64,70 $\%$.

Tabel 4. Jumlah Responden menurut Tingkat Umur Kelompok Tani Tumou Tou

\begin{tabular}{cccc}
\hline No & Umur (Tahun) & $\begin{array}{c}\text { Jumlah Responden } \\
\text { (Orang) }\end{array}$ & Persentase (\%) \\
\hline $\mathbf{1}$ & $31-40$ & 12 & 70,58 \\
$\mathbf{2}$ & $41-50$ & 4 & 17,64 \\
$\mathbf{3}$ & $51-60$ & 2 & 11,76 \\
\hline & Jumlah & 17 & 100,00 \\
\hline
\end{tabular}

Sedangkan hasil penelitian pada kelompok tani Tumou Tou, usia responden berkisar antara 3160 tahun, dan menujukan bahwa usia responden pada kelompok tani Tumou Tou lebih banyak bekisar antara 31-40 tahun yaitu sebanyak 12 orang atau $70,58 \%$.

\section{Pendidikan Responden}

Tingkah laku individu atau seseorang sangat dipengaruhi oleh pendidikan yang telah dicapai. Begitu pula pada anggota kelompok tani tingkat pendidikan mempengaruhi prilaku anggota kelompok dalam kelompok tani. Tenaga kerja dengan pendidikan tinggi akan cenderung aktif dalam kelompok.

Tingkat pendidikan kepada kelompok tani Suka Maju dapat dilihat pada Tabel 5.
Tabel 5. Jumlah Responden Tingkat Pendidikan Kelompok Tani Suka

\begin{tabular}{|c|c|c|c|}
\hline No & $\begin{array}{c}\text { Tingkat } \\
\text { Pendidikan }\end{array}$ & $\begin{array}{c}\text { Jumlah Responden } \\
\text { (Orang) }\end{array}$ & Persentase (\%) \\
\hline 1 & SD & 2 & 11,76 \\
\hline 2 & SMP & 2 & 11,76 \\
\hline 3 & SMA & 12 & 70,58 \\
\hline 4 & S1 & 1 & 5,88 \\
\hline & Jumlah & 17 & 100,00 \\
\hline
\end{tabular}

Data Primer 2019. Diolah.

Tabel 5 menujukan bahwa tingkat pendidikan responden kelompok tani Suka maju yang paling banyak yaitu SMA sebanyak 12 responden $(70,58 \%)$ tingkat SMP sebanyak 2 responden $(11,76 \%)$ dan tingkat pendidikat $\mathrm{S} 1$ paling sedikit yaitu 1 responden $(5,88 \%)$, sedangakan pendidikan SD sebanyak 2 responden $(11,76 \%)$.

Tingkat pendidikan kepada kelompok tani Tumou Tou dapat dilihat pada Tabel 6.

Tabel 6. Jumlah Responden Tingkat Pendidikan Kelompok Tani Tumou

\begin{tabular}{|c|c|c|c|}
\hline No & $\begin{array}{c}\text { Tingkat } \\
\text { Pendidikan }\end{array}$ & $\begin{array}{c}\text { Jumlah Responden } \\
\text { (Orang) }\end{array}$ & Persentase (\%) \\
\hline 1 & SD & 3 & 17,64 \\
\hline 2 & SMP & 4 & 23,56 \\
\hline 3 & SMA & 8 & 47,05 \\
\hline 4 & S1 & 2 & 11,76 \\
\hline \multicolumn{2}{|r|}{ Jumlah } & 17 & 100,00 \\
\hline
\end{tabular}

Data Primer 2019. Diolah.

Tingkat pendidikan responden pada kelompok tani Tumou Tou yang paling banyak yaitu SMA sebanyak 8 orang $(47,05 \%)$, tingkat SMP sebanyak 4 responden $(23,56 \%)$, pendidikan SD sebanyak $3(17,64 \%)$ dan tingkat pendidikan S1 2 responden $(11,76 \%)$.

\section{Modal Sosial dalam Kelompok Tani Norma}

Norma yang dimaksud dalam penelitian ini adalah sekumpulan aturan dalam kelompok tani yang diharapkan dipatuhi dan diikuti oleh seluruh anggota kelompok yang tergabung dalam kelompok. Rekapitulasi Norma dapat dilihat pada Tabel 7.

Tabel 7. Rekapitulasi Norma dalam Kelompok Tani Suka

\begin{tabular}{lcccc}
\multicolumn{3}{c}{ Maju dan Tumou Tou } \\
\hline Modal Sosial & \multicolumn{2}{c}{$\begin{array}{c}\text { Suka Maju } \\
(\mathbf{1 7} \text { Anggota) }\end{array}$} & \multicolumn{2}{c}{$\begin{array}{c}\text { Tomou Tou } \\
(\mathbf{1 7} \text { Anggota) }\end{array}$} \\
\cline { 2 - 6 } & $\begin{array}{c}\text { Baik } \\
(\%)\end{array}$ & $\begin{array}{c}\text { Kurang Baik } \\
(\%)\end{array}$ & $\begin{array}{c}\text { Baik } \\
(\%)\end{array}$ & $\begin{array}{c}\text { Kurang Baik } \\
(\%)\end{array}$ \\
\hline Norma & & & - & 100 \\
Peraturan & 100 & - & - & 100 \\
Sanksi & 100 & - & 76,47 & 23,52 \\
Keadilan & 100 & - & $\mathbf{2 5 , 4 9}$ & $\mathbf{7 4 , 5 0}$ \\
\hline Jumlah & $\mathbf{1 0 0}$ & - & &
\end{tabular}

Berdasarkan Tabel diatas, dapat diketahui bahwa Kelompok Tani Suka Maju memiliki nilai norma yang lebih baik daripada kelompok Tani Tumou Tou. 


\section{Jaringan}

Modal sosial tidak dibangun hanya oleh satu individu melaikan akan terletak pada kecenderungannya yang tumbuh dalam suatu kelompok untuk bersosialisasi sebagai bagian penting dari nilai-nilai yang melekat. Rekapitulasi Jaringan dalam kelompok tani Suka Maju dan Tumou Tou dapat dilihat pada Tabel 8 .

Tabel 8. Rekapitulasi Jaringan dalam Kelompok Tani Suka Maju dan Tumou Tou

\begin{tabular}{lcccc}
\hline \multicolumn{1}{c}{ Modal Sosial } & \multicolumn{1}{c}{$\begin{array}{c}\text { Suka Maju } \\
\text { (17 Anggota) }\end{array}$} & $\begin{array}{c}\text { Tumou Tou } \\
\text { (17 Anggota) }\end{array}$ \\
\cline { 2 - 5 } & $\begin{array}{l}\text { Baik } \\
(\%)\end{array}$ & $\begin{array}{l}\text { Kurang } \\
\text { Baik (\%) }\end{array}$ & $\begin{array}{l}\text { Baik } \\
(\%)\end{array}$ & $\begin{array}{l}\text { Kurang } \\
\text { Baik (\%) }\end{array}$ \\
\hline $\begin{array}{l}\text { Jaringan } \\
\text { Petani dengan } \\
\begin{array}{l}\text { Petani } \\
\text { Petani dengan }\end{array}\end{array}$ & 100 & - & 11,76 & 88,23 \\
$\begin{array}{l}\text { Petani Kelompok } \\
\text { Lain }\end{array}$ & 100 & - & 29,41 & 70,58 \\
$\begin{array}{l}\text { Petani dengan } \\
\text { Instansi } \\
\text { Pemerintah }\end{array}$ & 100 & - & & \\
\hline Jumlah & & & 70,58 & 29,41 \\
\hline Data Primer 2019. Diolah & $\mathbf{1 0 0}$ & - & $\mathbf{3 7 , 5 2}$ & $\mathbf{6 2 , 7 4}$ \\
\hline
\end{tabular}

Dapat dilihat bahwa 100\% anggota kelompok tani Suka Maju memiliki jaringan yang baik.

\section{Kepercayaan}

Saling percaya adalah bentuk keinginan mengambil resiko dalam hubungan-hubungan sosialnya yang didasari oleh perasaan yakin bahwa yang lain akan melakukan sesuatu seperti yang diharapkan dan akan senantiasa bertindak dalam suatu pola tindakan yang saling mendukung.

Tabel 9. Rekapitulasi Kepercayaan dalam Kelompok Tani Suka Maju dan Tumou Tou

\begin{tabular}{lcccc}
\multicolumn{1}{c}{ Modal Sosial } & \multicolumn{2}{c}{$\begin{array}{c}\text { Suka Maju } \\
\text { (17 Anggota) }\end{array}$} & \multicolumn{2}{c}{$\begin{array}{c}\text { Tumou Tou } \\
(\mathbf{1 7} \text { Anggota) }\end{array}$} \\
\cline { 2 - 5 } & $\begin{array}{l}\text { Baik } \\
(\%)\end{array}$ & $\begin{array}{l}\text { Kurang } \\
\text { Baik (\%) }\end{array}$ & $\begin{array}{l}\text { Baik } \\
(\%)\end{array}$ & $\begin{array}{l}\text { Kurang } \\
\text { Baik (\%) }\end{array}$ \\
\hline $\begin{array}{l}\text { Kepercayaan } \\
\text { Hubungan }\end{array}$ & 100 & - & 100 & - \\
$\begin{array}{l}\text { Sosial dengan } \\
\text { Instansi }\end{array}$ & & & & \\
$\begin{array}{l}\text { Pemerintahan } \\
\text { Harapan }\end{array}$ & 100 & - & & \\
\hline Jumlah & $\mathbf{1 0 0}$ & - & 94,11 & 5,88 \\
\hline
\end{tabular}

Dapat dilihat bahwa dalam Kelompok Tani Suka Maju maupun Kelompok Tani Tumou Tou memiliki Hubungan Sosial dengan Instansi Pemerintah yang baik (100\%).

\section{Hubungan Timbal Balik}

Timbal balik (reciprocity) merupakan salah satu elemen yang penting dalam modal sosial. Hubungan timbal balik ini juga dapat diartikan sebagai suatu hubungan yang saling melengkapi dan saling mendukung satu sama lain antar anggota kelompok. Rekapitulasi variabel Timbal Balik dapat dilihat dalam Tabel 10.

Tabel 10. Rekapitulasi Hubungan Timbal Balik Kelompok

\begin{tabular}{ccccc}
\multicolumn{3}{c}{ Tani Suka Maju dan Tumou Tou } \\
\hline Modal Sosial & \multicolumn{2}{c}{ Suka Maju } & \multicolumn{2}{c}{ Tumou Tou } \\
& $(\mathbf{1 7}$ Anggota) & (17 Anggota) \\
\cline { 2 - 5 } & Baik & Kurang & Baik & Kurang \\
& $(\%)$ & Baik $(\%)$ & $(\%)$ & Baik $(\%)$ \\
\hline
\end{tabular}

\begin{tabular}{lcccc} 
& $(\%)$ & Baik $(\%)$ & $(\%)$ & Baik $(\%)$ \\
\hline $\begin{array}{l}\text { Hub. Timbal } \\
\text { Balik }\end{array}$ & & & & \\
$\begin{array}{l}\text { Tingkat } \\
\text { Kepedulian }\end{array}$ & 100 & - & 100 & - \\
$\begin{array}{l}\text { Sosial } \\
\begin{array}{l}\text { Sikap Saling } \\
\text { Membantu }\end{array}\end{array}$ & & & & \\
\hline Jumlah & 100 & - & 100 & - \\
\hline & 100 & - & $\mathbf{1 0 0}$ & - \\
\hline
\end{tabular}

Data Primer 2019. Diolah.

Berdasarkan Tabel diatas, dapat diketahui bahwa semua anggota Kelompok Tani Suka Maju maupun Kelompok Tani Tumou Tou memilki hubungan timbal balik yang baik dalam tingkat kepedulian sosial dan sikap saling membantu.

\section{Nilai-Nilai}

Nilai-nilai adalah suatu ide yang dianggap benar dan penting oleh anggota komunitas dan diwariskan secara turun temurun. Rekapitulasi variabel nilai-nilai dapat dilihat pada Tabel 11.

Tabel 11. Rekapitulasi Nilai-Nilai dalam Kelompok Tani Suka Maju dan Tumou Tou

\begin{tabular}{ccccc}
\hline Modal Sosial & \multicolumn{2}{c}{$\begin{array}{c}\text { Suka Maju } \\
(\mathbf{1 7} \text { Anggota) }\end{array}$} & \multicolumn{2}{c}{$\begin{array}{c}\text { Tumou Tou } \\
(\mathbf{1 7} \text { Anggota) }\end{array}$} \\
\cline { 2 - 5 } & $\begin{array}{c}\text { Baik } \\
(\boldsymbol{\%})\end{array}$ & $\begin{array}{c}\text { Kurang Baik } \\
(\boldsymbol{\%})\end{array}$ & $\begin{array}{c}\text { Baik } \\
(\boldsymbol{\%})\end{array}$ & $\begin{array}{c}\text { Kurang Baik } \\
(\boldsymbol{\%})\end{array}$ \\
\hline Nilai - Nilai & & & & \\
Kerja Keras & 100 & - & 100 & - \\
Prestasi & 100 & - & 23,52 & 76,47 \\
\hline Jumlah & $\mathbf{1 0 0}$ & - & $\mathbf{6 1 , 7 6}$ & $\mathbf{3 8 , 2 3}$ \\
\hline Data Primer 2019. Diolah. & & &
\end{tabular}

Berdasarkan Tabel diatas, dapat dilihat bahwa baik kelompok tani Suka Maju maupun Tumou Tou memiliki nilai Kerja Keras yang baik. Kelompok Tani Suka Maju memiliki Nilai Prestasi yang baik dibandingkan dengan Kelompok Tani Tumou Tou.

\section{Rekapitulasi Modal Sosial dalam Kelompok Tani Suka Maju dan Kelompok Tani Tumou Tou}

Rekapitulasi hasil penelitian mengenai modal sosial dalam kelompok tani Suka Maju dan kelompok tani Tumou Tou dapat dilihat pada Tabel 12. 


\begin{tabular}{|c|c|c|c|c|c|}
\hline \multicolumn{3}{|c|}{$\begin{array}{c}\text { KELOMFOK TANI SUKA } \\
\text { MAJU }\end{array}$} & \multicolumn{3}{|c|}{$\begin{array}{l}\text { KELONPOKTANI } \\
\text { TUMOU TOU }\end{array}$} \\
\hline $\begin{array}{l}\text { MODAL. } \\
\text { SOSEAL. }\end{array}$ & $\begin{array}{l}\text { BAIK } \\
(4)\end{array}$ & $\begin{array}{c}\text { TIDAK } \\
\text { BAIK } \\
(46)\end{array}$ & $\begin{array}{l}\text { MODAL. } \\
\text { SOSIAL }\end{array}$ & $\begin{array}{c}\text { B.A } \\
\text { K } \\
(46)\end{array}$ & 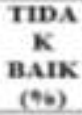 \\
\hline Nerma & 100 & 0 & Nerma & 25,49 & 74,50 \\
\hline Jariagaa & 100 & 0 & Jariagan & 37,25 & 62,74 \\
\hline Kepercayaan & 100 & 0 & Kepercayaan & 97,05 & 1.96 \\
\hline $\begin{array}{l}\text { Hubungan } \\
\text { Timbal Batik }\end{array}$ & 100 & 0 & $\begin{array}{l}\text { Hubuagas } \\
\text { Tiabal Balik }\end{array}$ & 100 & 0 \\
\hline Nilai - Nitai & 100 & 0 & Nillat - nillai & 61,76 & 38,23 \\
\hline Jumiah & 100 & e & Jemiah & 58,82 & 42,17 \\
\hline
\end{tabular}

Berdasarkan Tabel di atas, dapat dilihat bahwa kelompok tani Suka Maju sangat baik dalam menerapkan modal sosial di semua aspek dibandingkan dengan kelompok tani Tumou Tou.

\section{KESIMPULAN DAN SARAN}

\section{Kesimpulan}

Modal sosial telah mampu meningkatakan eksistensi serta kekompakan kelompok tani Suka Maju karena modal dari kelompok tani Suka Maju masih sangat baik di banding dengan kelompok tani Tumou Tou karena dilihat dari segala sisi Kelompok Tani Suka Maju lebih baik dalam menerapkan Modal Sosial. Dalam hal ini kelompok tani Tumou Tou dapat mengevaluasi kembali organisasinya dalam penerapan modal sosial agar kelompok tani Tumou Tou menjadi lebih baik lagi kedepanya.

\section{Saran}

Berasarkan kesimpulan diatas, Disarankan agar kelompok tani Suka Maju terus mempertahankan bahkan meningkatkan kerja sama yang dimiliki agar dapat menjadi contoh bagi kelompok tani lainnya di Desa Kopiwangker.

Kelompok tani Tumou Tou sebagai salah satu kelompok tani yang kurang aktif di desa Kopiwangker agar supaya bisa mengevaluasi kembali kelompoknya, seperti mengadakan pemilihan pengurus kelompok tani yang baru, dan anggota kelompok diharapkan membangkitkan kembali semangat bekerja sama bukan hanya memikirkan kepentingan pribadi tapi juga harus memikirkan kepentingan kelompok serta kelompok tani Tumou Tou harus mengadakan pertemuan rutin kelompok agar dapat menjalin hubungan kekeluargaan dan kerjasama yang baik.

\section{DAFTAR PUSTAKA}

Putnam, Robert, 1993. Sosial Capital. Pricenton Universty : Pricenton.

Suharto, E. 2007. Modal Sosial dan Kebijakan Publik. 